\title{
EFFECTS OF SCHEDULING ON SLEEP AND PERFORMANCE IN COMMERCIAL MOTORCOACH OPERATIONS
}

\author{
Lora Wu \& Gregory Belenky \\ Sleep and Performance Research Center, Washington State University \\ Spokane, Washington, USA \\ Email: ljwu@wsu.edu
}

\begin{abstract}
Summary: Maintaining cognitive alertness during commercial motorcoach operations is important for drivers as they are responsible for preventing, detecting, and managing errors. Schedules that do not follow circadian and homeostatic sleep principles may contribute to fatigue related events and accidents. The Federal Motor Carrier Safety Administration (FMCSA) has hoursof-service (HOS) regulations in place that allow motorcoach operators to work backwardly rotating 18-23 hour duty cycles (a duty cycle being the sum of HOS mandated on and off duty periods), requiring progressively earlier start times. Such schedules do not allow for sufficient and appropriately placed rest periods, resulting in fatigue and decreased performance. This study will investigate the effect of scheduling on sleep and performance in motorcoach operators. We are collecting objective and subjective data on sleep and performance of motorcoach drivers working under the current HOS regulations to observe the prevalence of circadian friendly and mismatched schedules, and the impact work schedules have on sleep and performance. This article describes the study design and methodology.
\end{abstract}

\section{INTRODUCTION}

Sleep loss degrades performance from the simplest to the most complex behaviors. Studies of normal subjects during both acute total sleep deprivation and chronic partial sleep restriction consistently reveal robust, replicable performance decrements (e.g., Thorne et al., 1985; Belenky et al., 2003; Van Dongen et al., 2003), reduced sleep latencies, and increased subjective sleepiness (e.g., Carskadon \& Dement, 1979). Additionally, sleep loss has been shown to affect decision making (Harrison \& Horne, 1999), which is implicated in complex processing and performance. Behavioral evidence indicates that higher order cognitive processes such as executive function are more severely affected than lower level cognitive processes (Harrison \& Horne, 2000; Nilsson et al., 2005). As successfully operating a motorcoach requires complex mental processes, managing sleep and fatigue in motorcoach drivers is important.

Alertness and performance are mediated in large measure by three factors: sleep/wake history, the endogenous circadian rhythm, and workload (Clegern et al., 2006; Dinges \& Kribbs, 1991; Dinges et al., 2005; Wesensten et al., 2004; Wesensten et al., 2005). Alertness and performance fluctuate across the 24-hour day in synchrony with - but lagging by approximately 3-4 hoursthe circadian rhythm in body temperature. Performance in well-rested persons is lowest between 0600-1000 hours and highest in mid-evening (Van Dongen \& Dinges, 2005). When the circadian rhythm is disrupted due to changes in light exposure relative to the habitual sleep period (e.g., night shift work, travel across time zones) sleep, alertness and performance are impaired 
(Åkerstedt, 2003; Folkard et al., 2005). In shift work or during abnormal work hours, desynchrony between circadian sleep/alertness tendency and work/sleep schedule results in chronically reduced performance and alertness during the night shift and inadequate sleep during the day. This is a consequence of (a) working through the circadian low when one would normally be asleep, and (b) attempting sleep during the circadian rise. Shift workers are unable to sleep more than approximately 5 hours during the day, which leads to chronic sleep restriction (Åkerstedt, 2003). Time on task interacts with sleep/wake history and circadian rhythm to further degrade performance (Angus et al. 1985; Doran et al. 2001; Findley et al. 1999; Gilberg \& Åkerstedt, 1998; Wesensten et al., 2004; Clegern et al., 2006).

Motorcoach operators work under hours-of-service (HOS) regulations established by the Federal Motor Carrier Safety Administration (FMCSA). These regulations apply to all companies that currently provide motorcoach services. Current rules indicate that operators can spend a maximum of 15 hours on-duty, a minimum of 8 hours off-duty, and a maximum of 10 hours driving. Under these rules, motorcoach operators can work 18-23 hour work/rest cycles. Strung together, these schedules can be either forward or backward rotating, and thus incompatible with circadian physiology. Under current commercial motorcoach operations, chronic sleep restriction (i.e., days or weeks with less than adequate sleep) is probable (Dinges et al., 2005; National Sleep Foundation, 2005). The essence of the problem of sustaining performance in the operational environment is the effective management of sleep, circadian rhythm, and time on task.

The HOS put forth by the FMCSA is a relevant topic, as driver fatigue contributes to many vehicular accidents (Maycock, 1997). Regardless, it is likely that the number of fatigue related accidents is underestimated (e.g., Knipling \& Wang, 1994). To elucidate the relationship between commercial driver fatigue and accidents, the NTSB studied single truck crashes that were likely to have been fatigue-related. Of the 107 accidents studied, 58\% were considered to have fatigue as a probable cause. Seventy of the 107 accidents occurred between 2200 and 0800 hours and, of these, about $74 \%$ were considered fatigue-related. The NTSB concluded that the most critical factors in predicting fatigue-related accidents were the duration of the most recent sleep period, the amount of sleep in the past 24 hours, and split sleep patterns (NTSB, 1995). This study indicated that nighttime driving is compounded by sleep deficits, producing a much higher rate of fatigue-related accidents than nighttime driving alone. Similarly, another study reported that there is an increased risk for accidents among drivers after 3-4 days of driving concludes with a nighttime drive (Jovanis, Kaneko, \& Lin, 1991).

Motorcoach operators' ability to take mid-shift breaks and naps varies with the type of operation. Operators driving a commuter express shift are guaranteed a mid shift break, while regular route, tour, and charter drivers are less likely to receive mid-shift breaks. We will monitor these rest periods and the sleep that occurs during rest to assess the utility of naps as a countermeasure to fatigue during operations. Research on short naps ( $\leq 30$ minutes) has demonstrated protective or restorative qualities on performance and fatigue (Brooks \& Lack, 2006; Hayashi et al. 1999; Philip et al., 2006; Takahashi \& Arito, 2000; Takahashi et al., 1998; Tietzel \& Lack, 2001).

Borbély (1982) proposed a two process model of sleep/wake regulation, based on the theory that sleep and wakefulness are mediated by sleep homeostasis and circadian factors. The U.S. Army 
and U.S. Air Force helped develop the Sleep, Activity, Fatigue and Task Effectiveness (SAFTE) model to use in their operations (Hursh et al., 2004). The model is well validated and has outperformed other models in predicting performance (Van Dongen, 2004). SAFTE is a biomathematical model accounting for sleep and work history and circadian rhythmicity to predict effectiveness, the opposite of fatigue (Hursh et al., 2006); its user interface is The Fatigue Avoidance Scheduling Tool (FAST) and together, the model and program are referred to as SAFTE/FAST. Known or estimated sleep and work periods are inputted to yield predicted effectiveness levels. Effectiveness is operationally defined as the inverse of fatigue, and is our proxy for performance. The model does not currently account for time on task effects or individual vulnerability to sleep restriction.

\section{STUDY}

The attempt to meet customer needs and to provide competitive services leads to schedules that may include long periods of driving. These long drives may contribute to fatigue and decreased performance in drivers. An improved understanding of how long shift duration, working at adverse circadian phase, and on-board rest affects sleep and cognitive performance may lead to improved safety for drivers and passengers. We investigate drivers' sleep and work schedules and cognitive performance using a naturalistic field study in order to examine current motorcoach operators' schedules.

The purpose of the study is to identify schedules and operations that have a high risk of fatigue, to examine if motorcoach schedules are providing drivers with an adequate opportunity for sleep, and if drivers are able to take advantage of the sleep opportunities provided, and to examine if drivers an adequate level of performance during scheduled trips. Additionally, we will assess the accuracy of fatigue models' predicted thresholds that could have safety consequences.

The Washington State University Institutional Review Board approved this study. We obtained a Certificate of Confidentiality from the National Institutes of Health.

\section{METHODS}

\section{Participants}

Sixty motorcoach drivers operating under the FMCSA HOS regulations will be recruited for a total $n=48$ after accounting for expected attrition. Active commercial motor vehicle driver status and current employment through an operational motorcoach company are inclusion criteria. Drivers driving one of the four types of services: charter (trips to and from an event), tour (multiday trips ranging from 3 days to 3 weeks), regular route (scheduled trips to and from set destinations), and commuter express operations (shuttle services to and from local destinations) will be recruited. Studied schedules will include extended work days; backward rotating, 18-23 hour duty cycles; driving between midnight and 0600 hours; irregular work schedules; and midshift breaks, all within the context of current hours of service regulations for motorcoach drivers. Drivers will be paid for participating in the study. 


\section{Design}

Each driver will be studied over the course of 30 days. Drivers will complete demographic, health, sleep, and workplace environment surveys. Participants will document work schedules in a duty diary, and driver logs will be collected when available.

The study of the relationship between sleep and performance depends on the ability to objectively measure both. Laboratory studies use a variety of computer-based cognitive tests to objectively measure performance, one of the most sensitive being the psychomotor vigilance task (PVT). The PVT is well-characterized unprepared simple reaction time test that is sensitive to both sleep loss and time on task (Wilkinson \& Houghton, 1982; Dinges \& Powell, 1985; Thorne et al., 2005; Wesensten et al., 2004). The PVT yields asymptotic performance in a few sessions (i.e., is not subject to lingering practice effects), and thus is suitable for repeated measures designs (Thorne et al., 2005). PVT sensitivity to sleep restriction is comparable to that of the multiple sleep latency test (MSLT) and simulated driving performance standard deviation of lane position (Balkin et al., 2004). The PVT has been shown to be sensitive to even mild sleep loss (Belenky et al., 2003; Van Dongen et al., 2003). A well-rested person will typically respond in less than 250 milliseconds (Belenky et al., 2003). In the field, objective measurement of performance is made with the PVT ported to a handheld device. In this study, participants take a five minute PVT before each shift, before and after each break $>90$ minutes, and at the end of a shift. Drivers will never take the PVT while driving and are instructed to skip a PVT administration if the test would conflict with his or her operational duties.

In the laboratory, objective measurement of sleep is done by polysomnography. In the field, sleep is measured objectively using the wrist-worn actigraph, a device that uses an accelerometer to detect arm movements and is scored using a validated computer-algorithm (Ancoli-Israel et al., 2003; Sadeh \& Acebo, 2002). Participants will wear an actigraph (Actiwatch Spectrum®, Minimitter Inc., Bend, Oregon) continuously during the 30 day study and will also use a paper and pencil sleep diary to keep track of sleep and to rate subjective sleep quality.

Subjective sleepiness (Karolinska Sleepiness Scale; range 1-9: 'very alert' to 'very sleepy, fighting sleep, an effort to keep awake'; Akerstedt \& Gillberg, 1990) and subjective fatigue (SamnPerelli Fatigue Scale; range 1-7: 'fully alert, wide awake' to 'completely exhausted, unable to function effectively'; Samn \& Perelli, 1982) are rated at the start of a shift, before and after each break $>90$ minutes, and at the end of a shift.

\section{Proposed Analyses}

Objective sleep (actigraph) and work (schedules and logs) data will be used as input to the SAFTE/FAST model to predict effectiveness during work periods. This will be correlated with objective performance (PVT) data. Mixed effects ANOVA will be used to compare participants' performance between trip types and test times. Subjective sleepiness and fatigue ratings will be correlated with performance and predicted effectiveness. 


\section{ACKNOWLEDGEMENTS}

Research supported by the Federal Motor Carrier Safety Administration.

\section{REFERENCES}

Åkerstedt, T., \& Gillberg, M. (1990). Subjective and objective sleepiness in the active individual. International Journal of Neuroscience, 52, 29-37.

Åkerstedt, T. (2003). Shift work and disturbed sleep/wakefulness. Occupational Medicine, 53, 89-94.

Ancoli-Israel, S., Cole, R., Alessi, C., Chambers, M., Moorcroft, W., \& Pollak, C. P. (2003). The role of actigraphy in the study of sleep and circadian rhythms. Sleep, 26(3), 342-392.

Angus, R. G., Heslegrave, R. J., \& Myles, M. S. (1985). Effects of prolonged sleep deprivation, with and without chronic exercise, on mood and performance. Psychophysiology, 22(3), 276282.

Balkin T. J., Bliese, P. D., Belenky, G., Sing, H., Thorne, D. R., Thomas, M., Redmond, D. P., Russo, M., \& Wesensten, N. J. (2004). Comparative utility of instruments for monitoring sleepiness-related performance decrements in the operational environment. Journal of Sleep Research, 13, 219-227.

Belenky, G., Wesensten, N. J., Thorne, D. R., Thomas, M. L., Sing, H. C., Redmond, D. P., Russo, M., \& Balkin, T. (2003). Patterns of performance degradation and restoration during sleep restriction and subsequent recovery: A sleep dose-response study. Journal of Sleep Research, 12(1), 1-12.

Borbély, A. A. (1982). A two process model of sleep regulation. Human Neurobiology, 1, 195204.

Brooks, A., \& Lack, L. (2006). A brief afternoon nap following nocturnal sleep restriction: Which nap duration is most recuperative? Sleep 29(6), 831-840.

Carskadon, M. A., \& Dement, W. C. (1979). Effects of total sleep loss on sleep tendency. Perceptual and Motor Skills, 48, 495-506.

Clegern, W. C., Van Dongen, H., Balkin, T. J., Wesensten, N. J., \& Belenky, G. (2006). Time on task effect of chronic sleep restriction. Sleep 29(Abstract Supplement), A134.

Dinges, D. F., \& Kribbs, N. B. (1991). Performing while sleepy: Effects of experimentally induced sleepiness. In T. M. Monk (Ed.) Sleep, Sleepiness and Performance (pp. 97-128). Chichester, England: John Wiley \& Sons.

Dinges, D. F., \& Powell, J. W. (1985). Microcomputer analyses of performance on a portable, simple visual RT task during sustained operations. Behavior Research Methods, Instruments, \& Computers 1985, 17, 652-55.

Dinges, D. F., Rogers, N. L., \& Baynard, M. D. (2005). Chronic sleep deprivation. In M. H. Kryger, T. Roth, \& W. C. Dement (Eds.) Principles and Practice of Sleep Medicine ( ${ }^{\text {th }}$ ed., pp. 67-76). Philadelphia, PA: Elsevier Saunders.

Doran, S. M., Van Dongen, H. P. A., \& Dinges, D. F. (2001). Sustained attention performance during sleep deprivation: Evidence of state instability. Archives of Italian Biology, 39(3), 253-67. 
Findley, L. J., Suratt, P. M., \& Dinges, D. F. (1999). Time-on-task decrements in "steer clear" performance of patients with sleep apnea and narcolepsy. Sleep, 15(22), 804-809.

Folkard, S., Lombardi, D.A., \& Tucker, P.T. (2005). Shiftwork: Safety, sleepiness and sleep. Industrial Health, 43, 20-23.

Gillberg, M., \& Akerstedt, T. (1998). Sleep loss and performance: No "safe" duration of a monotonous task. Physiology \& Behavior, 64(5), 599-604.

Harrison, Y., \& Horne, J. A. (1999). One night of sleep loss impairs innovative thinking and flexible decision making. Organizational Behavior and Human Decision Process, 78, 12845.

Harrison, Y., \& Horne, J. A. (2000). The impact of sleep deprivation on decision making: A review. Journal of Experimental Psychology: Applied, 6(3), 236-49.

Hayashi, M., Ito, S., \& Hori, T. (1999). The effects of a 20-min nap at noon on sleepiness, performance and EEG activity. International Journal of Psychophysiology, 32, 173-80.

Hursh, S. R., Raslear, T. G., Kaye, A. S., Fanzone, J. F., Jr. (2006). Validation and calibration of a fatigue assessment tool for railroad work schedules, summary report (DOT/FRA/ORD06/21). Washington, DC: U.S. Department of Transportation.

Hursh, S. R., Redmond, D. P., Johnson, M. L., Thorne, D. R., Belenky, G., Balkin, T. J., Storm, W. F., Miller, J. C., \& Eddy, D. R. (2004). Fatigue models for applied research in warfighting. Aviation, Space, and Environmental Medicine, 75(3), 44-53.

Jovanis, P. P., Kaneko, T., \& Lin, T.-D. (1991). Exploratory Analysis of Motor Carrier Accident Risk and Daily Driving Patterns. Transportation Research Group, University of California at Davis. Working Paper, No. 73.

Knipling, R. \& Wang, J.-S. (1994). Crashes and fatalities related to driver drowsiness/fatigue. Washington, DC: Office of crash avoidance research, US Department of Transportation. Research Note.

Maycock, G. (1997). Sleepiness and driving: The experience of UK car drivers. Accident Analysis and Prevention, 29, 453-462.

National Sleep Foundation. National Sleep Foundation Sleep in America Poll 2005. Retrieved from: http://www.sleepfoundation.org/_content/hottopics/2005_summary_of_findings.pdf.

National Transportation Safety Board. (1995). Factors that affect fatigue in heavy truck accidents. Volume 1: Analysis. (NTSB No. SS-95/01/ NTIS No. PB95-917001). Washington, DC: National Transportation Safety Board.

Nilsson, J. P., Soderstrom, M., Karlsson, A. U., Lenader, M., Akerstedt, T., Lindroth, N. E., \& Axelsson, J. (2005). Less effective executive functioning after one night's sleep deprivation. Journal of Sleep Research, 14(1), 1-6.

Philip, P., Taillard, J., Moore, N., Delord, S., Valtat, C., Sagspe, P., \& Bioulac, B. (2006). The effects of coffee and napping on nighttime highway driving: A randomized trial. Annals of Internal Medicine, 144, 785 -791.

Sadeh, A., \& Acebo C. (2002). The role of actigraphy in sleep medicine. Sleep Medicine Reviews, 6(2), 113-124. 
Samn, S. W., \& Perelli, L. P. (1982). Estimating aircraft fatigue: A technique with application to airline operations (Technical Report No. SAM-TR-82-21): USAF School of Medicine, Brooks AFB, TX.

Takahashi, M., \& Arito, H. (2000). Maintenance of alertness and performance by a brief nap after lunch under prior sleep deficit. Sleep, 23(6), 1-7.

Takahashi, M., Fukuda, H., \& Arito, H. (1998). Brief naps during post-lunch rest: Effects on alertness, performance, and autonomic balance. European Journal of Applied Physiology and Occupational Physiology, 78(2), 93-8.

Tietzel, A. J., \& Lack, L. C. (2001). The short-term benefits of brief and long naps following nocturnal sleep restriction. Sleep, 24(3), 293-300.

Thorne, D. R. (1985). The Walter Reed performance assessment battery. Neurobehavioral Toxicology \& Teratology, 7, 415-418.

Thorne, D. R., Johnson, D. E., Redmond, D. R., Sing, H. C., Belenky, G., \& Shapiro, J. M. (2005). The Walter Reed palm-held psychomotor vigilance test. Behavioral Research Methods, Instruments, and Computers, 37(1), 111-118.

Van Dongen, H.P.A. (2004). Comparison of mathematical model predictions to experimental data of fatigue and performance. Aviation, Space, and Environmental Medicine, 75, A15A36.

Van Dongen, H. P. A., \& Dinges, D. F. (2005). Circadian rhythms in sleepiness, alertness, and performance. In M. H. Kryger, T. Roth, \& W. C. Dement (Eds.) Principles and Practice of Sleep Medicine ( $4^{\text {th }}$ ed., pp. 435-443). Philadelphia, PA: Elsevier Saunders.

Van Dongen, H. P., Maislin, G., Mullington, J.M., \& Dinges, D.F. (2003). The cumulative cost of additional wakefulness: Dose-response effects on neurobehavioral functions and sleep physiology from chronic sleep restriction and total sleep deprivation. Sleep, 26(2), 117-126.

Wesensten, N. J., Belenky, G., \& Balkin, T.J. (2005). Cognitive readiness in network-centric operations. Parameters: US Army War College Quarterly; 35(1), 94-105.

Wesensten, N. J., Belenky, G., Thorne, D.R., Kautz, M.A., \& Balkin, T.J. (2004). Modafinil vs. caffeine: Effects on fatigue during sleep deprivation. Aviation Space and Environmental Medicine, 75(6), 520-525.

Wilkinson, R. T., \& Houghton, D. (1982). Field test of arousal: A portable reaction timer with data storage. Human Factors, 24, 487-493. 